\title{
Prevalence and Predictors of White Coat Hypertension among Newly-Diagnosed Hypertensive Patients in a Tertiary Health Centre in Nigeria
}

\author{
Bolade Dele-Ojo ${ }^{1 *}$, Philip Kolo ${ }^{2}$, Ayodele Ogunmodede ${ }^{2}$, Haleema Bello ${ }^{2}$, \\ Ibraheem Katibi, ${ }^{2}$ Ayodele Omotoso ${ }^{2}$, Samuel Dada ${ }^{1}$
}

\footnotetext{
OPEN ACCESS

Citation: BF Dele-Ojo, PM Kolo, JA Ogunmodede Prevalence and Predictors of White Coat Hypertension among NewlyDiagnosed Hypertensive Patients in a Tertiary Health Centre in Nigeria. Ethiop J Health Sci.2017;29(4):431.doi:http://dx.doi.org/

10.4314/ejhs.v29i4.3

Received: July 17, 2018

Accepted: September 18, 2018

Published: July 1, 2019

Copyright: (C) 2019 Dele-Ojo, B.F., et al .

This is an open access article distributed under the terms of the Creative Commons

Attribution License, which permits unrestricted use, distribution, and reproduction in any medium, provided the original author and source are credited. Funding: Nil

Competing Interests: The authors declare that this manuscript was approved by all authors in its form and that no competing interest exists.

Affiliation and Correspondence:

${ }^{1}$ Ekiti State University Ado Ekiti Ekiti State, Ado, Ekiti 360001, Nigeria

${ }^{2}$ University of Ilorin Teaching

Hospital, Ilorin, Nigeria

*Email:bolade.dele-ojo@eksu.edu.ng, owolabi_2008@yahoo.com
}

\section{ABSTRACT}

BACKGROUND: Failure to diagnose and adequately classify newly-diagnosed hypertensive patients may lead to non-recognition of White Coat Hypertension (WCH) and inappropriate use of antihypertensive medications. This study determined the prevalence and predictors of white coat hypertension among newly-diagnosed hypertensive patients in a tertiary health centre in Nigeria. METHODS: One hundred and twenty newly-diagnosed hypertensive patients and 120 controls were recruited for the study. All the participants had 24-hour Ambulatory Blood Pressure Monitoring (ABPM) using an oscillometric device (CONTEC $\left.{ }^{\circledR}\right)$. Data were analyzed using SPSS version 20.0. RESULTS: Out of 120 patients, 52 were males and the mean age was $44.2 \pm 9.7$ years whereas of the 120 controls, 53 were males and the mean age was $44.0 \pm 7.5$ years. The mean body mass index of the patients, BMI $\left(27.0 \pm 4.5 \mathrm{~kg} / \mathrm{m}^{2}\right)$ was higher than control $\left(24.1 \pm 4.5 \mathrm{~kg} / \mathrm{m}^{2}\right)$, p-value $<0.001$. The prevalence of $\mathrm{WCH}$ was $36.7 \%$. The mean age and $\mathrm{BMI}$ of those with $\mathrm{WCH}$ were $43.3 \pm$ 11.4 years and $26.4 \pm 4.5 \mathrm{~kg} / \mathrm{m} 2$ respectively. Females constituted a greater proportion (70.5\%). In multivariate analysis, high level of education and being overweight or obese were significant determinants of $\mathrm{WCH}$. CONCLUSION: High prevalence of WCH existed among participants studied. High level of education and being obese were predictors of white coat hypertension. Hence, ambulatory blood pressure monitoring should be included as part of routine work-up for newly-diagnosed hypertensive patients in order to limit the number of those who may be committed to lifelong antihypertensive medications with its unwanted side effects.

KEYWORDS: Prevalence, white coat hypertension, ambulatory blood pressure, predictor, Nigeria.

\section{INTRODUCTION}

Systemic hypertension ( $\mathrm{SH}$ ) is a global public health problem and a leading cause of death worldwide (1). It is known to run a rapid course in Blacks (2). Its diagnosis is usually made using the office 
blood pressure measurement. However, there are limitations to its use (3). Studies have shown that 24hour Ambulatory Blood Pressure Measurements (ABPM) is a stronger predictor of all-cause and cardiovascular mortality than office BP measurement (4-6), 24-hour ABPM provides automated Blood Pressure (BP) measurements during a 24-hour period while subjects are engaged in their usual activities, including sleep without the doctor's influence. If used for all newly diagnosed hypertensive patients, it will aid in identifying BP phenotypes such as White Coat Hypertension (WCH) and masked hypertension $(4,5)$. Consequently, fewer drug treatments will be necessary, and there will be reduction in the risk of adverse drugs reaction that may result from unnecessary pharmacologic treatment of WCH (7).

The use of ABPM is still relatively uncommon in Nigeria (8). Hence, limited data exist on the prevalence and predictors of $\mathrm{WCH}$ in the Country. However, a recent meta-analysis in African populations revealed that $\mathrm{WCH}$ is frequent; hence, the need for out-of-clinic BP measurement in the diagnosis and management of patients with hypertension in Africa (9). Additionally, it has been reported that the prevalence of white coat hypertension can vary from $12 \%$ to $60 \%$ depending on patients' selection (10).

This study, therefore, determined the prevalence of $\mathrm{WCH}$ and the predictors of WCH among newlydiagnosed hypertensive patients in a tertiary health Centre in Nigeria.

\section{MATERIALS AND METHODS}

Study design and area: The study was a crosssectional survey conducted in North Central Nigeria.

Inclusion criteria: The Patients were drug naïve newly-diagnosed hypertensive while the controls were apparently healthy sex and age-matched adults with normal blood pressure (BP $\leq 140 / 90 \mathrm{mmHg}$ ).

Exclusion criteria: Pregnant women, those with other cardiovascular diseases and co-morbidities were excluded from both study groups.

Study protocol: The study population consisted of 240 individuals that included 120 patients with newly-diagnosed systemic hypertension and 120 control participants, seen at the Medical Outpatient Departments at the University of Ilorin Teaching Hospital. All eligible participants were informed about the study, and informed consent was obtained.
Thereafter, each participant completed a selfadministered questionnaire. Participants' confidentiality was maintained by using codes instead of names and keeping the data away from non-members of the research team.

Sample size calculation/sampling technique: The sample size was calculated using the formula for cross-sectional survey (11) using prevalence of systemic hypertension of $19.3 \%$ in Sub-Saharan African (12), 95\% confidence interval, degree of accuracy of 0.05 and attrition rate of $10 \%$ to give a minimum sample size of 236 . For population less than 10,000 , a correction factor, $\mathrm{N}_{\mathrm{f}}=\mathrm{n} / 1+(\mathrm{n} / \mathrm{N})$ was used to determine the final sample size, where $n$ is the calculated sample size, $\mathrm{N}$ is the total number of newly-diagnosed patients seen at the Out-Patient Department in one year $(\mathrm{N}=144)$. Therefore, $\mathrm{N}_{\mathrm{f}}=$ $236 / 2.63888, \mathrm{~N}_{\mathrm{f}}=89$. Giving the attrition risk of $20 \%$, the sample size was increased to include 120 patients and 120 controls. Hence, 120 patients and 120 control participants were recruited. The sampling technique used was consecutive, in which every participant that met the inclusion criteria was selected.

Ethical approval: Ethical approval was obtained from the Ethical Review Committee of the University of Ilorin Teaching Hospital (UITH), Ilorin, before the commencement of the study.

Statistical analysis: Statistical analysis was done with SPSS version 20.0. The results were expressed in tables with percentages. Quantitative and qualitative demographic characteristics were summarized and presented in tabular forms. Data were expressed as mean \pm standard deviation (SD) while frequencies were expressed as percentages. The Student t-test was used to compare the means of continuous variables between two groups that were normally distributed while analysis of variance was used to compare the means of normally distributed continuous variables that were more than two groups. Chi-square was used to compare proportions. Multivariate analysis was examined by logistic regression for the predictors of $\mathrm{WCH}$. The results were presented as the odds ratio with corresponding $95 \%$ confidence interval. For all tests, $p$-value $<0.05$ was considered statistically significant.

Measurements: The patients were antihypertensivenaïve adults whose mean (three measurements) BP was $\geq 140 / 90 \mathrm{mmHg}$. ABPMs were carried out on all

DOI: http://dx.doi.org/10.4314/ejhs.v29i4.3 
the study participants. ABPM was performed with an oscillometric device (CONTEC $\AA$ ), which was revalidated regularly against a mercury column sphygmomanometer. In the office, after a 5-minute rest with the participant seated, the BP measurements were taken with a mercury sphygmomanometer using an appropriate cuff, taken on the bare arm, which was supported and maintained at the heart's level. The mean of 3 measurements was used as the office BP. Thereafter, ABPM was fixed on each participant with measurements taken every 30 minutes from $7 \mathrm{a} . \mathrm{m}$. to 9.59 p.m. and every 1 hour from 10:00 p.m. to 6.59 am while the participant maintained his/her usual activities throughout the day. The appropriate cuff for the arm's circumference was placed on the nondominant arm, and the participants were instructed to maintain their arm stretched out at the heart level and be still during automatic BP measurements. Using the European Society of Hypertension (ESH) guidelines for the management of hypertension's cut-off limits; Normal day-time and mean 24-hour ABPM were $135 / 85 \mathrm{mmHg}$ and $130 / 80 \mathrm{mmHg}$ respectively, but night-time ABPM was placed at $120 / 80 \mathrm{mmHg}$ (3).

Participants were divided into subgroups based on the office BP and ABPM:
A. Individuals who were hypertensive by both methods were referred to as those with true or sustained systemic hypertension.

B. Individuals who were hypertensive by clinic measurement and normotensive by ambulatory measurement were referred to as those with white coat hypertension $(\mathrm{WCH})$.

C. Individuals who were normotensive by both methods were referred to as truly normotensive individuals.

D. Individuals who were normotensive by clinic measurement and hypertensive by ambulatory measurement were referred to as those with masked hypertension $(\mathrm{MH})$.

WCH is defined as office $\mathrm{BP} \geq 140 / 90 \mathrm{mmHg}$ but normal day-time ambulatory $\mathrm{BP}<135 / 85 \mathrm{mmHg}$. The Statistical Software for Social Sciences (SPSS 20) was used to analyze the data.

\section{RESULTS}

The demographic, anthropometric and clinical parameters of the study participants: A total of 240 participants consisting of 120 patients and 120 healthy controls were studied. The demographic, clinical and anthropometric parameters of the study participants are presented in Table 1.

TABLE 1. The demographic, anthropometric and clinical parameters of the study participants

\begin{tabular}{|c|c|c|c|}
\hline VARIABLES & $\begin{array}{l}\text { HYPERTENSIVE } \\
\mathrm{MEAN} \pm \text { SD /n (\%) }\end{array}$ & $\begin{array}{l}\text { CONTROL } \\
\mathrm{MEAN} \pm \mathrm{SD} / \mathrm{n}(\%)\end{array}$ & $\rho$-value \\
\hline Male n (\%) & $52(43.3)$ & $53(44.2)$ & 0.897 \\
\hline Female n $(\%)$ & $68(56.7)$ & $67(55.8)$ & 0.897 \\
\hline Age (years) & $44.2 \pm 9.7$ & $44.0 \pm 7.5$ & 0.403 \\
\hline Weight (kg) & $75.0 \pm 12.4$ & $67.1 \pm 12.3$ & $<0.001^{*}$ \\
\hline Height (m) & $1.67 \pm 0.08$ & $1.67 \pm 0.10$ & 0.356 \\
\hline $\mathrm{BMI}\left(\mathrm{kg} / \mathrm{m}^{2}\right)$ & $27.0 \pm 4.5$ & $24.1 \pm 4.2$ & $<0.001^{*}$ \\
\hline $\mathrm{WC}(\mathrm{cm})$ & $90.2 \pm 13.1$ & $82.7 \pm 11.8$ & $<0.001^{*}$ \\
\hline $\mathrm{HC}(\mathrm{cm})$ & $101.2 \pm 11.8$ & $96.2 \pm 9.8$ & $<0.001^{*}$ \\
\hline Waist-Hip Ratio & $0.89 \pm 0.09$ & $0.86 \pm 0.06$ & 0.101 \\
\hline Pulse Rate(bpm) & $80.5 \pm 13.2$ & $75.3 \pm 11.8$ & 0.468 \\
\hline Office SBP (mmHg) & $153.4 \pm 16.9$ & $116.8 \pm 10.9$ & $<0.001^{*}$ \\
\hline Office DBP (mmHg) & $96.2 \pm 12.1$ & $71.9 \pm 8.9$ & $<0.001^{*}$ \\
\hline Family history of SH (\%) & $82(68.3 \%)$ & $51(42.5 \%)$ & $<0.001^{*}$ \\
\hline Smoking n (\%) & $5(4.2 \%)$ & $3(2.5 \%)$ & 0.474 \\
\hline Alcohol consumption $(\%)$ & $7(5.8 \%)$ & $5(4.2 \%)$ & 0.556 \\
\hline \multicolumn{4}{|c|}{$\begin{array}{l}\text { Key: } * \text { = Statistically significant, } \mathrm{SD}=\text { Standard deviation, } \mathrm{BMI}=\text { Body mass index, } \mathrm{WC}=\text { Waist circumference, } \mathrm{HC}=\text { Hip } \\
\text { circumference, } \mathrm{SBP}=\text { Systolic blood pressure, DBP }=\text { Diastolic blood pressure, } \mathrm{SH}=\text { Systemic hypertension, bpm = beats per } \\
\text { minute }\end{array}$} \\
\hline \multicolumn{2}{|c|}{$\begin{array}{l}\text { The mean weight and waist circumference of the } \\
\text { patients }(75.0 \pm 12.4 \mathrm{~kg} \text { and } 90.2 \pm 13.1 \mathrm{~cm}) \text { were } \\
\text { higher than the mean weight and waist }\end{array}$} & \multicolumn{2}{|c|}{$\begin{array}{l}\text { circumference of the control participants }(67.1 \pm \\
12.3 \mathrm{~kg} \text { and } 82.7 \pm 11.8 \mathrm{~cm}) ; \mathrm{p} \text {-values }<0.001 \text { and } \\
<0.001 \text { respectively. The mean BMI of the }\end{array}$} \\
\hline
\end{tabular}

DOI: http://dx.doi.org/10.4314/ejhs.v29i4.3 
patients $\left(27.0 \pm 4.5 \mathrm{~g} / \mathrm{m}^{2}\right)$ was greater than the control participants $\left(24.1 \pm 4.5 \mathrm{~kg} / \mathrm{m}^{2}\right)$, p-value $<0.001$. In the hypertensive group, $68.3 \%$ had positive family history of $\mathrm{SH}$ compared with $42.5 \%$ in the control group; p-value $<0.001$. However, the mean office SBP and DBP in patients $(153.4 \pm 16.9 \mathrm{mmHg}$ and $96.2 \pm$ $12.1 \mathrm{mmHg}$ ) respectively were significantly higher than the mean office SBP and DBP in the control group $(116.8 \pm 11.0$ and $71.9 \pm 8.9 \mathrm{mmHg}) ; \mathrm{p}$ values $<0.001$ and $<0.001$ respectively. Prevalence and characteristics of White Coat Hypertension: Among the patients' group, the prevalence of white coat hypertension (WCH) was
$36.7 \%$ as shown in Figure 1. Systemic hypertension $(\mathrm{SH}), \mathrm{WCH}$ and truly normotensive groups were classified as groups $\mathrm{A}, \mathrm{B}$ and $\mathrm{C}$ respectively.

As illustrated in Table 2, a greater proportion of those with WCH were females $(70.5 \%)$. Compared with group A $(44.7 \pm 8.8$ years $)$ and group C $(42.4 \pm 7.7$ years $)$; -value $=0.222$. Also, there is no significant difference in the BMI of WCH group $\left(26.4 \pm 4.5 \mathrm{~kg} / \mathrm{m}^{2}\right)$ compared with group A $\left(27.5 \pm 4.3 \mathrm{~kg} / \mathrm{m}^{2}\right)$ and group $\mathrm{C}(24.0 \pm 4.2$ $\mathrm{kg} / \mathrm{m}^{2}$ ). However, the BMI of group A was significantly greater than group $\mathrm{C} ; \mathrm{p}$-value $<0.001$.

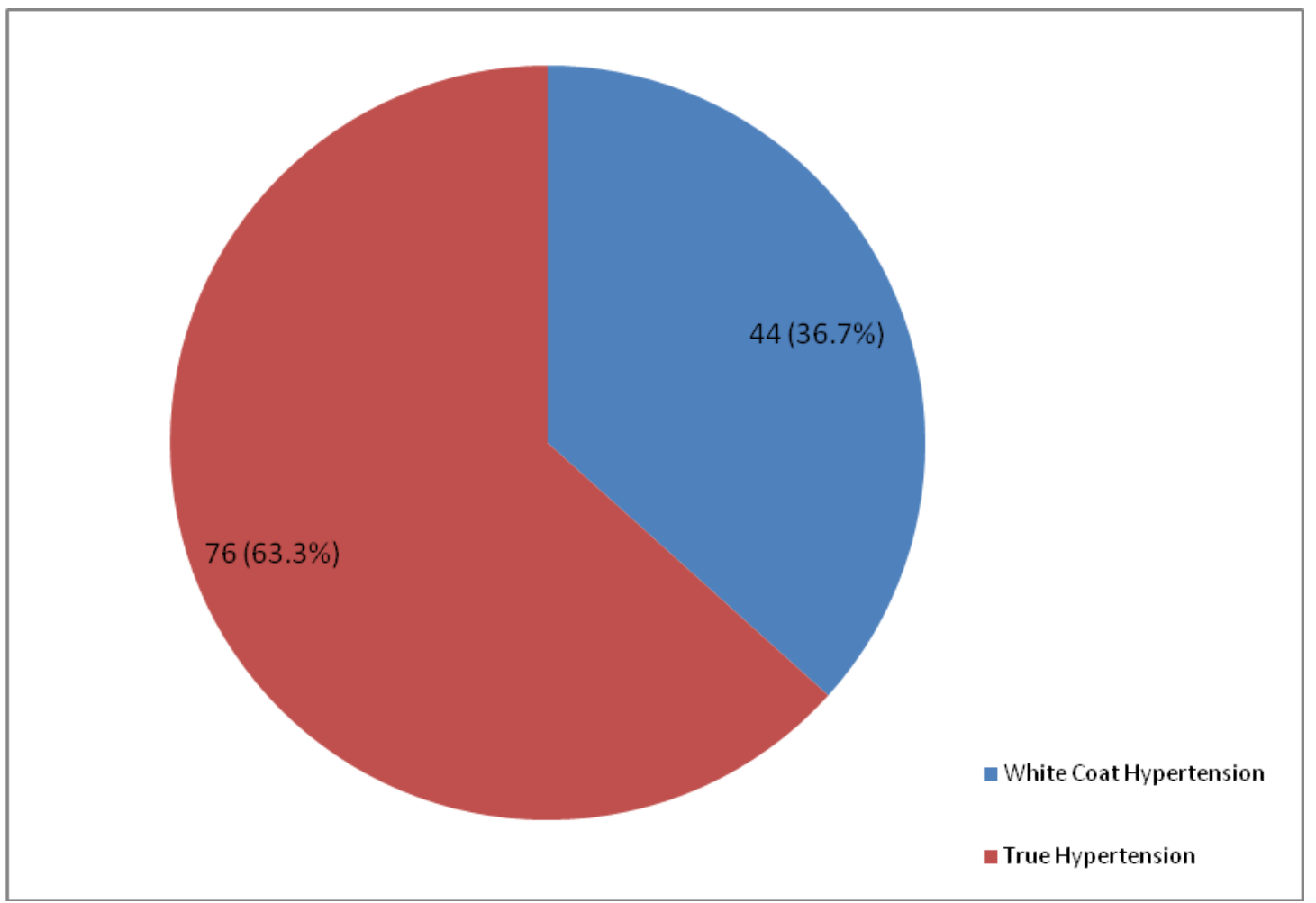

Figure 1: The Prevalence of white coat hypertension among patients with newly-diagnosed SH

The office and ambulatory blood pressure indices of the $\mathrm{WCH}$ in comparison with $\mathrm{SH}$ and truly normotensive group: The clinical parameters of participants in the three groups are shown in Table 2. The office SBP and DBP in the WCH group $(144.2 \pm 12.2$ and $88.3 \pm 10.3 \mathrm{mmHg})$ were intermediate between groups A $(158.0 \pm 17.7 \mathrm{mmHg}$ and $100.2 \pm 11.4 \mathrm{mmHg})$ and $\mathrm{C}$ $(117.0 \pm 11.7 \mathrm{mmHg}$ and $72.3 \pm 9.6 \mathrm{mmHg})$ respectively: p-values $<0.001$ and $<0.001$. The ambulatory day-time SBP and DBP in the WCH group $(124.5 \pm 6.0$ and $74.5 \pm 5.3 \mathrm{mmHg})$ were intermediate between groups A $(145.4 \pm 11.5$ and $91.3 \pm 9.7 \mathrm{mmHg})$ and group $\mathrm{C}(116.2 \pm 8.7 \mathrm{mmHg}$ and $69.4 \pm 7.2 \mathrm{mmHg}$ ): -values $<0.001$ and $<0.001$ respectively. Similarly, the ambulatory night-time SBP and DBP in the WCH group (118.6 \pm 8.5 and $69.2 \pm 5.7 \mathrm{mmHg}$ ) were intermediate between 
groups A $(140.0 \pm 16.0$ and $84.2 \pm 10.7 \mathrm{mmHg})$ and $\quad<0.001$ and $<0.001$ respectively.

group C (108.8 \pm 9.2 and $61.8 \pm 7.6 \mathrm{mmHg}): \mathrm{p}$-values

Table 2: The anthropometric and ambulatory parameters of the participants with true $\mathrm{SH}, \mathrm{WCH}$ and normal blood pressure

\begin{tabular}{|c|c|c|c|c|}
\hline VARIABLES & $\begin{array}{l}\text { TRUE SH (A) } \\
\text { MEAN } \pm \text { SD }\end{array}$ & $\begin{array}{l}\text { WCH (B) } \\
\operatorname{MEAN} \pm \text { SD }\end{array}$ & $\begin{array}{l}\text { NORMOTENSIVE } \\
\text { (C) } \\
\text { MEAN } \pm \text { SD }\end{array}$ & $\rho$-value \\
\hline Age (years) & $44.7 \pm 8.8$ & $43.3 \pm 11.4$ & $42.41 \pm 7.7$ & 0.222 \\
\hline $\mathrm{BMI}\left(\mathrm{kg} / \mathrm{m}^{2}\right)$ & $27.5 \pm 4.3$ & $26.4 \pm 4.5$ & $24.0 \pm 4.2$ & $<0.001^{\pi \odot}$ \\
\hline WC (cm) & $91.8 \pm 11.3$ & $87.3 \pm 15.4$ & $82.5 \pm 11.9$ & $<0.001^{\pi}$ \\
\hline Office SBP & $158.0 \pm 17.7$ & $144.2 \pm 12.2$ & $117.0 \pm 11.7$ & $<0.001^{\Omega \pi \#}$ \\
\hline Office DBP & $100.2 \pm 11.4$ & $88.3 \pm 10.3$ & $72.3 \pm 9.6$ & $<0.001^{\Omega \pi \neq}$ \\
\hline $\begin{array}{l}\text { Ambulatory daytime } \\
\text { SBP }\end{array}$ & $145.7 \pm 11.5$ & $124.5 \pm 6.0$ & $116.2 \pm 8.7$ & $<0.001^{\Omega \pi \neq}$ \\
\hline $\begin{array}{l}\text { Ambulatory daytime } \\
\text { DBP }\end{array}$ & $91.3 \pm 9.7$ & $74.5 \pm 5.3$ & $69.4 \pm 7.2$ & $<0.001^{\Omega \pi \#}$ \\
\hline $\begin{array}{l}\text { Ambulatory } \\
\text { nighttime SBP }\end{array}$ & $140.0 \pm 16.0$ & $118.6 .0 \pm 8.5$ & $108.8 \pm 9.2$ & $<0.001^{\Omega \pi \neq}$ \\
\hline $\begin{array}{l}\text { Ambulatory } \\
\text { nighttime DBP }\end{array}$ & $84.2 \pm 10.5$ & $69.2 \pm 5.7$ & $61.8 \pm 7.6$ & $<0.001^{\Omega \pi \neq}$ \\
\hline $\begin{array}{l}\text { Ambulatory daytime } \\
\text { pulse rate }\end{array}$ & $85.8 \pm 10.7$ & $79.4 \pm 9.2$ & $78.5 \pm 9.6$ & $<0.001^{\Omega \pi \neq}$ \\
\hline $\begin{array}{l}\text { Ambulatory daytime } \\
\text { pulse pressure }\end{array}$ & $53.8 \pm 8.7$ & $50.3 \pm 6.5$ & $46.7 \pm 6.1$ & $<0.001^{\Omega \pi \neq}$ \\
\hline
\end{tabular}

Key: $\Omega$, A statistically greater than $\mathrm{B} ; \pi$, A statistically greater than $\mathrm{C}$; $¥$, B statistically greater than $\mathrm{C}$; $\mathrm{C}$, B statistically greater than $\mathrm{A} ; \mu, \mathrm{C}$ statistically greater than $\mathrm{A} ; €, \mathrm{C}$ statistically greater than $\mathrm{B} ; \mathrm{WCH}$, White coat hypertension; SH, Systemic hypertension; SD, Standard deviation; BMI, Body mass index; WC, Waist circumference; HC, Hip circumference; SBP, Systolic blood pressure; DBP, Diastolic blood pressure

Predictors of WCH: Multivariate analysis showed that high level of education [odds ratio (OR) $12.378,95 \%$ confidence interval (CI) 2.167 $70.709, \mathrm{p}=0.005]$ and being overweight/obese (OR $0.227,95 \%$ confidence interval (CI) 0.056 -

Table 3: Predictors of White Coat Hypertension

\begin{tabular}{lllll}
\hline Predictor variable & Categories of variable & OR & CI (95\%) & $\rho$-value \\
Age & - & 1.009 & $0.952-1.071$ & 0.755 \\
Sex & & 1.621 & $0.503-5.228$ & 0.418 \\
Level of education & Others (ref.) & 12.378 & $2.167-70.709$ & 0.005 \\
Family history of & & 0.787 & $0.260-2.383$ & 0.672 \\
hypertension & & & & 0.038 \\
Overweight/obese & Normal (ref.) & 0.227 & $0.056-0.920$ & 0.038 \\
\hline
\end{tabular}

OR, odds ratio; CI, confidence interval, Predictors: Level of education, overweight/obese

\section{DISCUSSION}

This study has demonstrated the usefulness of ABPM for proper diagnosis and classification of patients. ABPM has enabled the diagnosis of a potentially enigmatic $\mathrm{SH}$ subtype such as white
$0.920, p=0.038)$ were predictors of white coat hypertension as shown in Table 3 . WCH was not significantly associated with age, sex, and family history of hypertension.

DOI: http://dx.doi.org/10.4314/ejhs.v29i4.3 
both studies, patients with newly diagnosed hypertension being more prone to the white-coat effect than patients with long-standing hypertension. Also, in this study, office BP were taken manually using the standard mercury sphygmomanometer rather than the automated sphygmomanometer used by Isiguzo et al. This could also account for lower prevalence of WCH in their study because automated oscillometric BP sphygmomanometer has been shown to give lower BP values (14). Takah et al. reported $25 \%$ among Cameroonians (15) whereas Abir-Khalil et al. reported $33 \%$ as the prevalence of $\mathrm{WCH}$ in Morocco, North Africa (16). However, the prevalence in our study falls within the range of $24 \%$ to $39 \%$ that was reported by Fagard et al (17) in a European study population. Verdecchia et al. reported that depending also on the selection of patients and groups of patients, the prevalence of white coat hypertension can vary from $12 \%$ to $60 \%(10)$.

Understanding the likely profile of individuals with $\mathrm{WCH}$ will facilitate the selection of patients for ABPM. In this study, higher level of education and being overweight or obese were significant predictors of white coat hypertension. People with higher level of education are more likely to be gainfully employed and financially buoyant to eat more which predispose to the likelihood of being overweight or obese. Additionally, obese patients usually have higher office BP; hence, they exhibit larger clinic-awake differences compared with their non-obese counterparts. Studies of the association between BMI and ABPM variables have shown conflicting findings. Takah et al. found BMI to be the only determinant of WCH (15), whereas Ben-Dov et al. found no association between BMI and $\mathrm{WCH}$ in a large retrospective study of patients referred for ABPM (18). Worth mentioning is the fact that female gender, age and family history of hypertension were not associated with $\mathrm{WCH}$ in this study. This concurred with findings by Takah et al. in Cameroon which also showed that age, sex, and family history of hypertension were not associated with $\mathrm{WCH}$ in their study population (13). However, on the contrary, some studies have shown that female gender, age, and family history of hypertension were determinants of WCH (19-
21). Accounting for the conflicting findings in the predictors could be differences in the study population. Most previous studies were carried out in different parts of the world other than the Nigerian population. Hence, there is a need to carry out more future studies on the predictors of WCH in our study population.

Although individuals with $\mathrm{WCH}$ might not require pharmacotherapy immediately, there is a need to follow them up regularly for early detection of incident true hypertension and also encourage them to adopt non-pharmacologic strategies such as lifestyle modification. This is strengthened by findings from a prospective study by Verdecchia et al which showed that $37 \%$ of their WCH patients spontaneously developed incident true $\mathrm{SH}$ during a follow-up that ranged from 6 months to 6 years (22).

The recognition of $\mathrm{WCH}$ is important for treatment initiation, as this sub-group will only require lifestyle modification and follow-up, rather than pharmacotherapy (7). Aside the hypotensionrelated complications that could arise from unnecessary pharmacotherapy of individuals with $\mathrm{WCH}$, it is also waste of resources especially in a country where the majority of the population spend 'out of pocket' for healthcare (23). Therefore, identification of this BP phenotype would result in a net reduction in the cost of managing $\mathrm{SH}$, thereby guaranteeing judicious and efficient utilization of healthcare resources and improved population health outcome.

This study, unlike the previous one in Nigeria, also examined predictors of $\mathrm{WCH}$. The study is cross-sectional; therefore, causal inference cannot be drawn. It is limited to one tertiary hospital in Nigeria. Hence, a multi-centre study will be necessary.

There was a high prevalence of $\mathrm{WCH}$ among the studied participants. High level of education and being overweight or obese were significant determinants of white coat hypertension. Hence, there is a need to include ABPM as part of routine work-up for newly-diagnosed hypertensives who are highly educated and obese in order to limit the number of those who may be committed to lifelong antihypertensive medications with its unwanted side effects.

DOI: http://dx.doi.org/10.4314/ejhs.v29i4.3 


\section{REFERENCES}

1. Nandhini S. Essential Hypertension. A Review Article. $J$ Pharm Sci Res. 2014;6(9):305.

2. 2. Mayet J, Shahi M, Foale RA, Thom SAM, Poulter NR, Server PS. Racial differences in cardiac structure and function in essential hypertension. BMJ. 1994;308:1011.

3. Chobanian AV, Bakris GL, Black HR, et al. The Seventh Report of the Joint National Committee on Prevention, Detection, Evaluation and Treatment of High Blood Pressure. JAMA 2003;289:2560-72.

4. BanegasJR, Ruilope LM, dela Sierra A, et al. Relationship between Clinic and Ambulatory Blood Pressure Measurements and Mortality.N Eng J Med. 2018;378(16): 15091520.

5. Mancia G, Fagard R, Narkiewicz K, Redon J, Zanchwetti A, Bohm M. Guidelines for the management of arterial hypertension: The Task Force for the management of arterial hypertension of the European Society of Hypertension (ESH) and of the European Society of Cardiology (ESC). J Hypertens. 2013;31:1281-357.

6. Staessen JA, Thijs L, Fagard R, O'Brien ET, Clement D, De Leeuw PW. Predicting cardiovascular risk using conventional vs ambulatory blood pressure in older patients with systolic hypertension in Europe Trial Investigators. JAMA. 1999;282:539-46.

7. James PA, Oparil S, Carter BL, et al. 2014 evidence-based guideline for the management of high blood pressure in adults: report from the panel members appointed to the Eighth Joint National Committee (JNC 8). JAMA 2014;311(5):507-20.

8. Isiguzo GC, Baugh D, Nwuruku GC, Mezue KN, Madu C, Madu EC. Initial experience with 24-h ambulatory blood pressure monitoring in Nigerian patients with hypertension. Nig J Cardiol 2016;13:33-8.

9. Noubiap JJ,Nansseu JR,Nkeck JR,Nyaga UF,Bigna JJ. Prevalence of white coat and masked hypertension in Africa: A systematic review and meta-analysis.J Clin Hypertens (Greenwich) 2018; 20:1165-1172.
10. Verdecchia P, Schillaci G, Boldrini F, Zampi I, Porcella C.Variability Between Current Definitions of 'Normal' Ambulatory Blood Pressure. Implications in the Assessment of White Coat Hypertension. Hypertension 1992; 20(4): 555-562

11. Araoye MO. Research Methodology with Statistics for Health and Social sciences. Ilorin: Nathadex Press; 2003:115-121.

12. Hendriks ME, Wit FWNM, Roos MTL, et al. Hypertension in sub-Sahara Africa: Cross sectional surveys in Four Rural and Urban Communities. PLOS One 2012;7:1-9.

13. Brien EO, Coats A, Owens P, et al. Use and interpretation of ambulatory blood pressure Society. BMJ 2000;320:1128-34.

14. Myers MG, McInnis NH, Fodor GJ, Leenen FH. Comparison Between an Automated and Manual Sphygmomanometer in a Population Survey. American Journal of Hypertension 2008; 21:280-283.

15. Takah N, Dzudie A, Ndjebet J, et. al. Ambulatory blood pressure measurement in the main cities of Cameroon: prevalence of masked and white coat hypertension, and influence of body mass index. The Pan African Medical Journal 2014;19:240.

16. Abir-Khalil S, Zaimi S, Tazi MA, Bendahmane S, Bensaoud O, Benomar $\mathrm{M}$. Prevalence and predictors of white-coat hypertension in a large database of ambulatory blood pressure monitoring. Easter Mediterr Heal J. 2009;15(2):400-407.

17. Fagard RH, Stolarz K, Kuznetsova T, et al. Sympathetic activity, assessed by power spectral analysis of heart rate variability, in white-coat, masked and sustained hypertension versus true normotension. $J$ Hypertens 2007;25(11):2280-5.

18. Ben-Dov IZ, Mekler J, Bursztyn M. Sex differences in ambulatory blood pressure monitoring. Am J Med 2008;121:509-514.

19. Chin-Chou H, Tao-Cheng W, Shing-Jong L, Jaw-Wen C, Hsin-Bang L. Clinical Predictors of Significant White-Coat Effect in NonDiabetic Hypertensive Patients. Acta Cardiol Sin 2010: 26: 151-156.

DOI: http://dx.doi.org/10.4314/ejhs.v29i4.3 
20. Myers MG, Reeves RA. White coat effect in treated hypertensive patients: sex differences. J Hum Hypertens 1995;9:729-33.

21. Dolan E, Stanton A, Atkins N, et al. Determinants of white-coat hypertension. Blood Press Monit 2004;9:307-309.

22. Verdecchia P, Clement D, Fagard R. Blood Pressure Monitoring. Task force III. Target organ damage, morbidity and mortality. Blood Press Monit 1999;4:303-317.

23. Ayanleye OA. A legal appraisal of the national health insurance scheme in Nigerian Journal of Public and Private Law, Faculty of Law, Nnamdi Azikwe University, Awka. 2013;5: 106-117.

DOI: http://dx.doi.org/10.4314/ejhs.v29i4.3 